\title{
MÁS ALLÁ DE LAS FRONTERAS: IDENTIDADES LIMINALES EN LA FICCIÓN TELEVISIVA HANNIBAL, DE BRYAN FULLER
}

\author{
BEYOND BOUNDARIES: LIMINAL IDENTITIES \\ IN BRYAN FULLER'S HANNIBAL TELEVISION FICTION
}

Leire AZKUNAGA-GARCÍA

Universidad del País Vasco (UPV / EHU)

leire.azkunaga@ehu.eus

\begin{abstract}
Resumen: Hannibal se presenta como un paradigma de las transformaciones que han sufrido las ficciones contemporáneas en los últimos años al introducir al otro, al villano, como protagonista del relato. La identidad del caníbal se conforma mediante conceptos culturalmente contrapuestos y se sitúa en un continuo entre: entre el bien y el mal, entre la monstruosidad y la humanidad, entre el horror de los crímenes que comete y la estetización y el preciosismo de cómo los presenta, entre la recreación de una exquisita alta cultura (gastronomía) y la animalidad y el salvajismo (canibalismo) que puntúa todos y cada uno de sus episodios.
\end{abstract}

Palabras clave: Hannibal. Hannibal Lecter. Bryan Fuller. Canibalismo. Liminalidad. Alteridad. Ficción televisiva.

Abstract: Hannibal is presented as a paradigm of the transformations that contemporary fictions have undergone in recent years by introducing the other, the villain, as the main character of the story. The identity of the cannibal is formed by culturally opposed concepts and is placed in a continuous between: between good and evil, between monstrosity and humanity, between the horror of the crimes he commits and the aestheticization and preciousness of how he presents them, between the recreation of an exquisite high culture (gastronomy) and animality and savagery (cannibalism) that scores each and every one of its episodes. 
Key Words: Hannibal. Hannibal Lecter. Bryan Fuller. Cannibalism. Liminality. Otherness. Television fiction.

\section{HACIA UNA NUEVA CONCEPCIÓN DE BELLEZA Y FEALDAD}

Tradicionalmente, el bien se ha relacionado con la idea belleza y, hasta el barroco, con obras que gozasen de una armonía y equilibrio y en las que predominase la luz y la claridad. El mal, unido al concepto de fealdad, era presentado en escenas de tensión y oscuridad, pues recreaban lo perverso y resultaban desagradables o repugnantes para los seres humanos. La fealdad en el arte es entendida, esencialmente, como la antítesis de lo bello, como "una carencia de armonía que viola las reglas de la proporción" (Eco, 2005: 133). No obstante, ambos conceptos son, tal y como reafirma Eco, mutables, puesto que su concepción varía en cada cultura y época histórica (2005: 14). La misma idea es reafirmada por Nietzsche quien asegura que los humanos establecen una serie de parámetros para determinar aquello que debe ser considerado bello (2004: 606).

Uno de los sentimientos ligados al concepto de la fealdad es el asco. Al igual que predominan los estudios del concepto de la belleza sobre los de la fealdad (Eco, 2007: 8), hallamos en el asco un campo de estudio poco tratado (Miller, 1997; Kolnai, 2013). A grandes rasgos, el asco puede definirse como una reacción de defensa humana o una "emoción repulsiva" (McGinn, 2016: 15) ante un ser u objeto que genera disgusto. Es, en palabras de Kolnai, el "grado más intenso del desagrado" (2013: 38). El asco se relaciona directamente con los sentidos, ya que se origina en el plano estético. A diferencia del miedo o el odio, en donde se requiere la existencia directa del sujeto u objeto amenazante, para el asco es tan solo necesaria su "esencia", la apariencia misma remite a ese sentimiento perturbador (Kolnai, 2013: 47).

Es la búsqueda de la supresión u omisión de estos sentimientos lo que llama McGinn "represión apetitiva". Tal y como afirma Edmund Burke (1757) y comparte con Eco (2007: 423), es la distancia de seguridad a la hora de contemplar en el arte escenas violentas o desagradables lo que transforma el miedo en un horror delicioso, un placer negativo que permite 
no sólo su disfrute, sino también la fascinación por este tipo de escenas. El sentimiento del asco genera un efecto ambivalente muy similar. Kolnai (2013) llama macabra atracción al deseo contradictorio de distanciamiento y acercamiento al objeto. "Es una clase de glamour negativo", en donde "la psique humana se deja seducir por el interés, la excepcionalidad y la potencia mágica del objeto que repugna" (McGinn, 2016: 56).

Otro concepto al que se asocia un sentimiento de malestar a la hora de contemplar ciertas imágenes es lo siniestro. Es entendido como aquella sensación de inquietud que experimentan las personas al contemplar aquello que no es conocido o familiar y que despierta el interés de los individuos, independientemente de que asuste o perturbe. Sigmund Freud (1954) reafirmaba esta idea al recordar que el termino alemán unheimlich (siniestro) como la antítesis de heimlich (confortable, tranquilo). Para Freud, siguiendo las ideas de Nietzsche, los humanos son una especie reprimida, unos agentes cognitivos que rechazan sus impulsos más puros y son sustituidos únicamente por aquellos que puedan ser aceptados por su círculo más cercano. En palabras de Eugenio Trías, lo siniestro no es solamente esa emoción oculta de los individuos, pues constituye, también, el límite y condición de lo bello. Es esa "capacidad por revelar y a la vez esconder lo siniestro" lo que hace que una obra sea concebida como algo bello (1982: 75).

Un sentimiento más profundo es el de la abyección. La figura de lo abyecto hace referencia a la vivencia del terror en su forma más tangible, la física o la orgánica, y está unida a la perversión. De modo que se podría definir lo abyecto como aquel sentimiento que se manifiesta como consecuencia de algo que aterroriza. Se trata de una sensación que invade el cuerpo de los individuos e incluso puede llegar a corromperlos. "Lo abyecto nos confronta con esos estados frágiles en donde el hombre erra en los territorios de lo animal" (Kristeva, 2004: 21). Lo abyecto es aquello no permitido en la sociedad, un tabú. En ese sentido, Kristeva coloca en la palestra el cadáver como la máxima figura de la abyección (2004: 11) y rescata los ejemplos de las mayores "abominaciones" consideradas por la biblia como son la muerte, el incesto y el canibalismo.

El canibalismo es una de las prácticas más rechazadas por los seres humanos (Miller, 1997; McGinn, 2016) y son los sentimientos, exteriorizados de forma natural como el asco, los que cumplen, de acuerdo con McGinn, una función de crítica social. Estas concepciones, asimiladas 
por los individuos, permiten discernir la belleza de la fealdad, lo permitido de lo rechazado en sociedad. "El asco es la poderosa fuerza necesaria para equilibrar nuestras desmesuradas tendencias: nos mantiene a raya cuando sentimos la compulsión de romper las cadenas de todo control decoroso" (McGinn, 2016: 129). Tal y como afirma Miller, el rechazo que sienten los seres humanos hacia determinadas imágenes desempeña un rol vital en la estructuración del mundo, si bien tiene una poderosa capacidad para generar imágenes y un papel fundamental para organizar las actitudes humanas. Y es que este sentimiento "ayuda a definir los límites que se establecen entre ellos y nosotros, entre tú y yo. Ayuda a evitar que nuestro modo quede subsumido a $s u$ modo. El asco, junto con el deseo, establece los límites del otro" (Miller, 1997: 83).

Partiendo de ello, la presente investigación pretende ahondar en dos bloques temáticos. En primer lugar, se abordará el concepto del canibalismo del protagonista homónimo de la ficción televisiva Hannibal (Bryan Fuller, 2013-2015). Lecter es un ser completamente liminal que esconde en sus lindes a un esteta caníbal, que se mueve entre el puro salvajismo y la absoluta sofisticación. Es también el otro, el carismático y despreciable villano que convive en aparente normalidad en sociedad.

En segundo lugar, se realizará una reflexión en torno al arte salvaje que propone el protagonista. A través de él se plantea una nueva concepción de arte que se contrapone con la clásica teoría de la belleza y la fealdad. Por medio de la delicada presentación de sus asesinatos (est) éticos, no sólo es representado el mal como algo aparentemente bello, sino que se les confiere una nueva significación a sus recreaciones de obras de arte clásicas.

\section{LA ALTERIDAD Y LA LIMINALIDAD EN HANNIBAL}

Se podría decir que la ambigüedad y el carácter liminal que adopta el objeto de estudio están presentes en todo momento y se manifiesta tanto en el plano narrativo y formal como en la construcción y presentación de sus personajes. En primer lugar, la ficción seriales construida en base al universo narrativo creado por Thomas Harris de sus novelas, principalmente El dragón rojo (1981) y Hannibal (1999), y en sus adaptaciones a la gran pantalla. El objetivo de la ficción no consiste tanto en servir como una 
adaptación fiel de los hechos narrados en las novelas y filmes, sino más bien de reinterpretarlos desde un nuevo punto de vista, de ofrecer "una relectura del universo lecteriano" (Piñeiro-Otero, 2016: 186). Esa retrocontinuidad a la que nos referimos permite distanciarse a la narración de la concepción tradicional del héroe protagónico y construir un relato más cercano de su antagonista Hannibal Lecter.

Es el villano el que protagoniza la ficción junto a su discípulo, Will Graham, un personaje que no tardará en corromperse. De esta manera, se pone en escena al otro, al salvaje asesino que se contrapone al nosotros civilizado. La controversia se da, precisamente, en el carácter liminal de esta figura antagónica, que sin parecerlo (sin poseer una apariencia monstruosa) encarna en su ser el salvajismo y brutalidad característicos de un monstruo de terror. La impasibilidad a la hora de cometer sus asesinatos -de no sentir emociones como el del asco- confirma su falta de humanidad (Miller, 1997: 35). No es considerado un hombre, pero sí una clase de monstruo humano (Oleson, 2005: 29).

La ficción refleja esa ambivalencia del personaje a través del plano formal por medio de su estética preciosista. La denominada estética del horror tiene como fin embellecer el mal, la perversión, a través de la ralentización o prolongación temporal de las escenas de lucha violenta -similar a las del arte barroco-, de los asesinatos (est)éticos creados por el protagonista y de la bella puesta en escena de los suculentos -y muy apetecibles- platos caníbales. Abordaremos mediante estas dos últimas la paradigmática figura de "Hannibal el Caníbal".

\section{1. "Eat The Rude": el canibalismo ético de Lecter}

Ya en los primeros minutos de la ficción se advierte a la audiencia del tono general que tomará la serie. El opening de Hannibal, de escasos veinte segundos, muestra sobre un fondo blanco la imagen de un líquido de color rojizo fluyendo a través de la pantalla. Mediante una puesta en escena un tanto hipnótica, la sangre (símbolo del salvajismo) y el vino (de la sofisticación) brotan a cámara lenta al ritmo de una música instrumental. La sangre tomará nuevamente ese cariz estético en las escenas bellohorrorosas de lucha en las que la sangre y los movimientos de los luchadores se verán ralentizados.

El mencionado líquido rojo comienza a moldear una figura abstracta, 
un tanto ambigua, pero reconocible para los espectadores. El salvajismo del protagonista queda oculto bajo un manto de sofisticación y elegancia, de la invisible máscara con la que viste y convive su brutal protagonista [Figura 1]. Esa hibridación del personaje se plasma claramente en la música clásica -Bach, Chopin, Beethoven o Debussy- que le acompaña a lo largo de la ficción. "La serie de Bryan Fuller es un oxímoron violento y perpetuo, que se empeña en colisionar opuestos: disfrute y dolor, hermosura y espanto, gore y gourmet, el refinamiento y la bestialidad, el canibalismo y la haute cuisine" (Nahum García, 2018: 98).

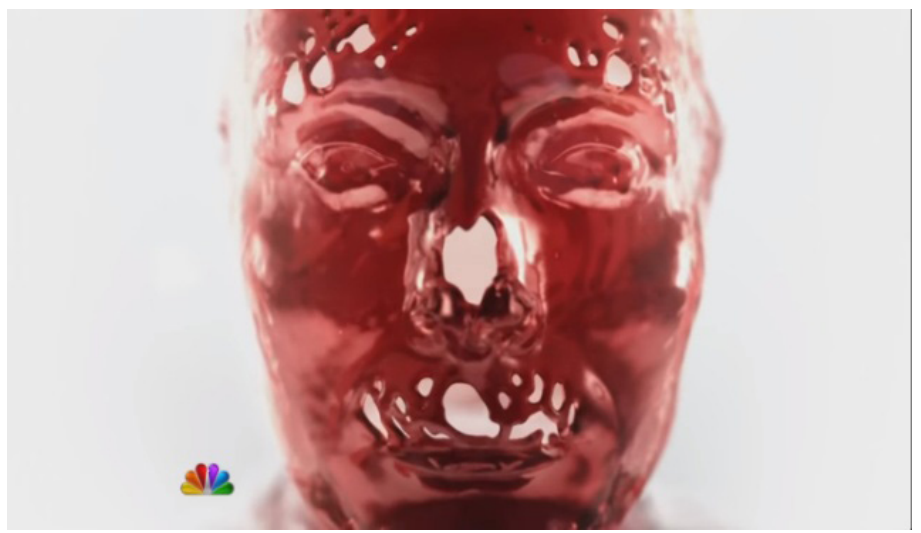

Figura 1

Siguiendo con la línea de algunas ficciones contemporáneas, la serie de televisión Hannibal sitúa la figura del villano, al otro, en el centro neurálgico del relato. Su protagonista no sóloes un experimentado asesino, sino también un ferviente defensor del canibalismo. El eslogan de la serie "eat the rude" (cómete al grosero), puede leerse también como el lema de la práctica primitiva que desarrolla el psiquiatra.

El continuo juego que se establece con la figura liminal del culto y salvaje protagonista se refleja en el modelo ideado por el antropólogo Claude Lévi-Strauss del "triángulo culinario". Lecter simboliza lo que el autor denominaba como lo crudo, pues se sitúa entre la cultura y la naturaleza. Sus víctimas son, por una parte, la carne cruda cocinada 
por el caníbal e integrada como el ingrediente principal en sus cenas (transformación cultural). Los cuerpos le servirán, además, a Lecter para crear su inconfundible arte homicida. Sin embargo, estas imágenes poseen una fecha de caducidad temprana, pues no tardarán en descomponerse para llegar a ese último estadio al que apuntaba Strauss (lo podrido) [Figura 2].

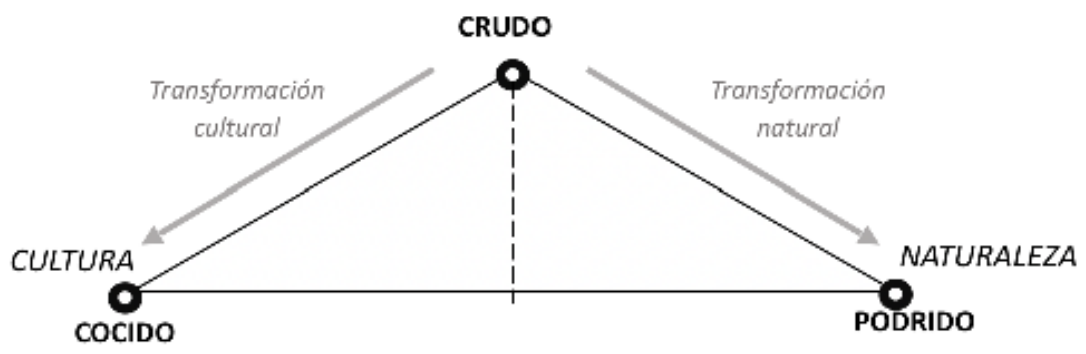

Figura 2. Elaboración propia a partir del modelo del "Triángulo culinario", de Claude Lévi-Strauss.

Hannibal no interviene en el proceso de descomposición de los cuerpos, pues se trata de una transformación natural. No obstante, se podría decir que su intención es mostrar cómo la belleza puede también corromperse o pudrirse. Hannibal contrasta la bella concepción del arte con el objeto primordial del asco: la putrefacción (Kolnai, 2013: 60). Las obras de arte del caníbal llegan a reflejar un escenario todavía más macabro al verse descomponer por el paso del tiempo. Lecter traslada, así, la idea fugacidad de la belleza, igualmente efímera que el de una vida.

Los menús caníbales cruzan también las fronteras de lo salvaje y lo civilizado. Son inherentemente liminales porque transgreden los límites entre lo interior y exterior, el otro y el nosotros (Fuchs \& Philips, 2018: 615). Por otro lado, la comida refuerza el sistema de valores y los límites culturales, entre lo que se puede (culturalmente aceptado) y lo que no se puede comer (subcultura, salvajismo). La comida se convierte no sólo en un sustento, sino también en parte de nuestra identidad como cultura. 
"Un alimento solo se ve abyecto cuando es un borde entre dos entidades o territorios distintos. Frontera entre naturaleza y la cultura, entre lo humano y lo no-humano" (Kristeva, 2004: 101).

Por otro lado, el personaje de Hannibal Lecter es conocido, ya desde la saga, por su prestigio en el campo de la psiquiatría. En su reclusión en el Hospital Psiquiátrico de Baltimore Lecter aprovecha para escribir numerosos artículos científicos. Resulta cuando menos contradictorio que un psicópata tan claro como Hannibal sea capaz de elaborar tan brillantes investigaciones sobre, precisamente, esa área de estudio. Su ambivalencia se manifiesta en esa doble imagen del protagonista. Es, en el mismo sentido, un médico y un asesino, un curandero y un implacable homicida.

Los detallados y deliberados asesinatos demuestran el amplio conocimiento que posee de medicina, así como su interés y especial dominio de la cirugía. Mediante pequeñas incisiones extrae los órganos deseados de sus víctimas o practica el despiece humano para acoplar correctamente los cuerpos escogidos en sus obras artísticas. Llama la atención uno de los primeros asesinatos en el que el caníbal recrea un antiguo boceto quirúrgico ("Entrée", 1x06). La ilustración "The woundman" (hombre herido) sirvió en los siglos XIV y XV en Europa como un modelo para orientar a los médicos en la cura de lesiones y heridas. Sin embargo, Lecter invierte el significado original de la obra y lo utiliza como una guía para el asesinato. Lejos de emplear el boceto para salvar una vida, el caníbal se beneficia de él, precisamente, para arrebatársela [Figuras 3 y 4]. 


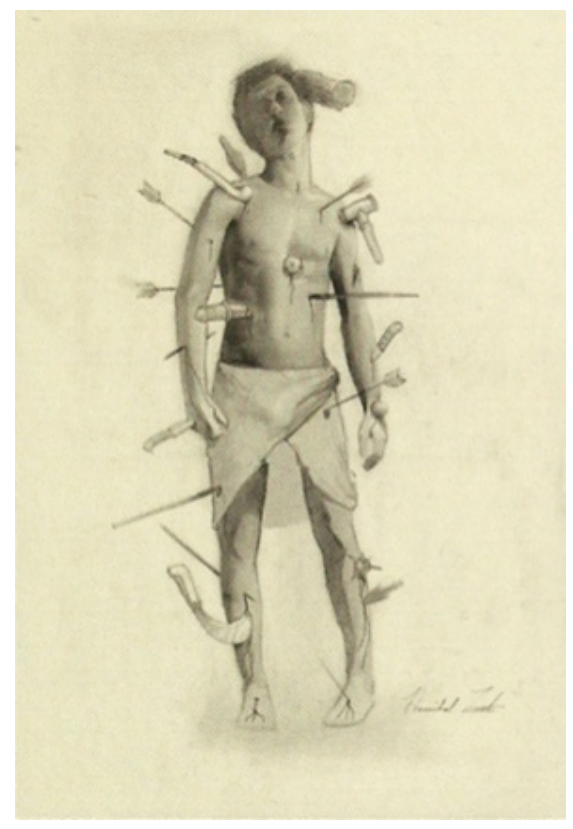

Figura 3

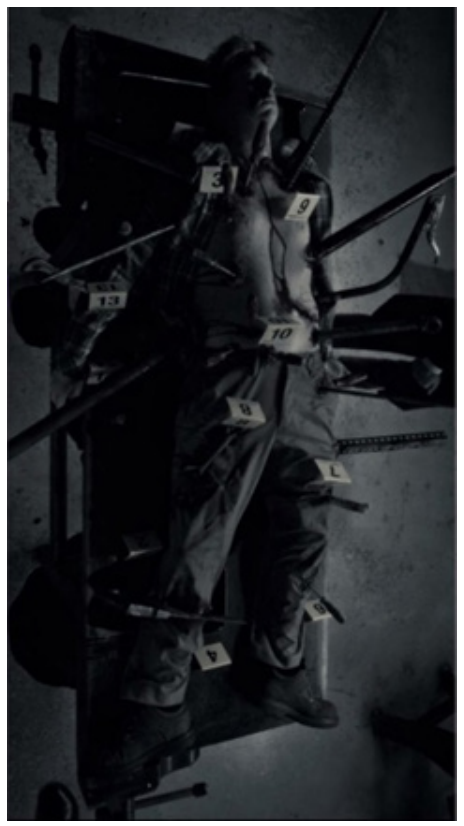

Figura 4

Hannibal ejerce el canibalismo no como rito, sino como práctica individual. Comete sus crímenes no movido por actos pasionales o impulsivos, sino tras haber deliberado, aplicando su propio "código ético", quién será su nueva víctima y cómo se compondrá la puesta en escena del crimen. Mencionamos aquí tres claros ejemplos en los que Lecter ha ejercido como un juez amoral al dictaminar su propia sentencia para sancionar el comportamiento "grosero" de varios sujetos. Y es que su mundo se mantiene a través de la violencia, donde la justicia se convierte en otra consideración estética más (Bainbridge, 2018: 610).

En primer lugar, cabe señalar el crimen que perpetra con el juez que instruye el caso de Will Graham ("Hassun", 2x03). En esta ocasión, Lecter desea realizar una crítica social a la justicia y para ello coloca al juez en la misma posición que el cuadro que tiene tras de sí. Como gran parte de las obras que recrea el caníbal, se trata de una obra barroca: El triunfo de la justicia de Gabriel Metsu (1660) [Figuras 5 y 6]. Este asesinato (est) ético resulta todavía más perverso al colocar a su víctima no sólo en la 
posición de la mujer del cuadro, sino también con la cabeza abierta y con su cerebro y corazón colocados sobre la balanza. El mensaje de este asesinato artístico es claro, pues así lo indica el propio Lecter cuando finge revisar la escena del crimen: "La justicia no sólo es ciega, tampoco tiene sentido ni corazón".

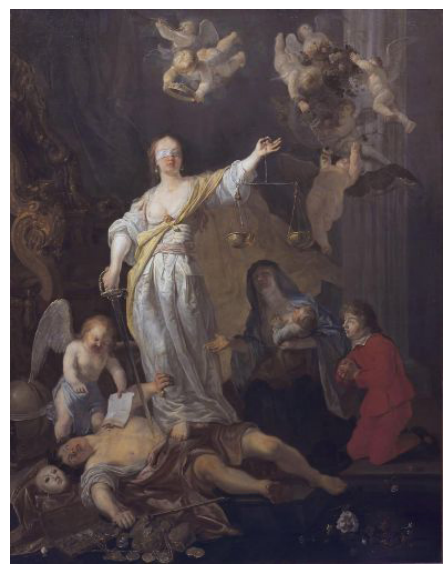

Figura 5

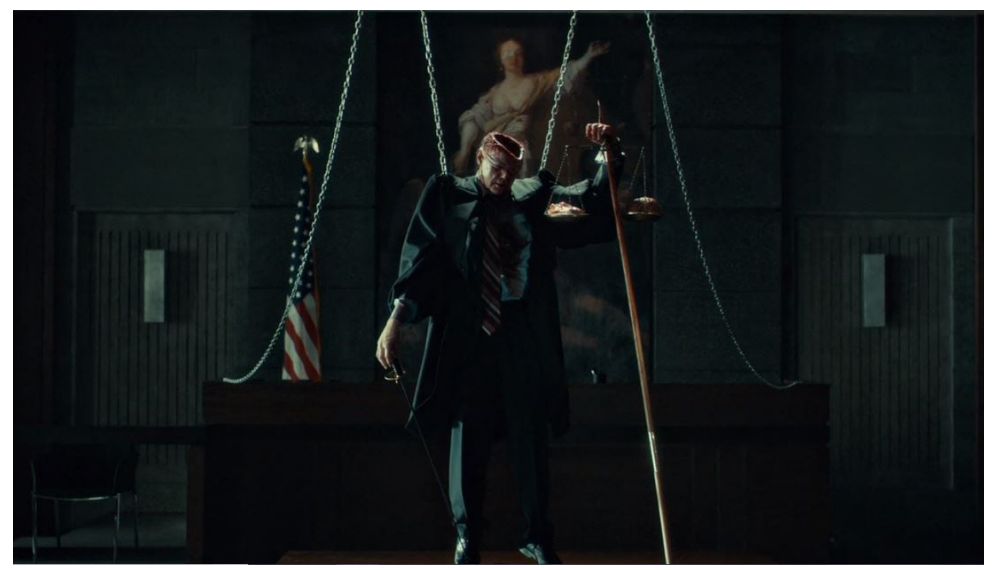

Figura 6 
Un final similar le concede a la forense Beverly Katz. La joven es descubierta merodeando en la casa del caníbal en busca de pruebas incriminatorias. Esa imperdonable falta de decoro de la forense hace que Hannibal decida, en honor a su profesión, dividida en varias secciones ("Mukozuke", 2x05). El cuerpo fragmentado de Beverly es colocado sobre láminas con formol, similar al arte que practica Damien Hirst en Some Comfort Gained from the Acceptance of Inherent Lies in Everything donde diseccionade la misma manera el cuerpo de una vaca [Figuras 7 y 8].

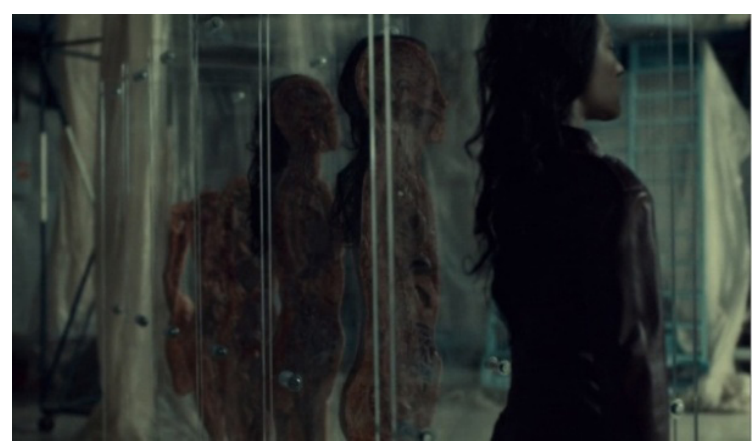

Figura 7

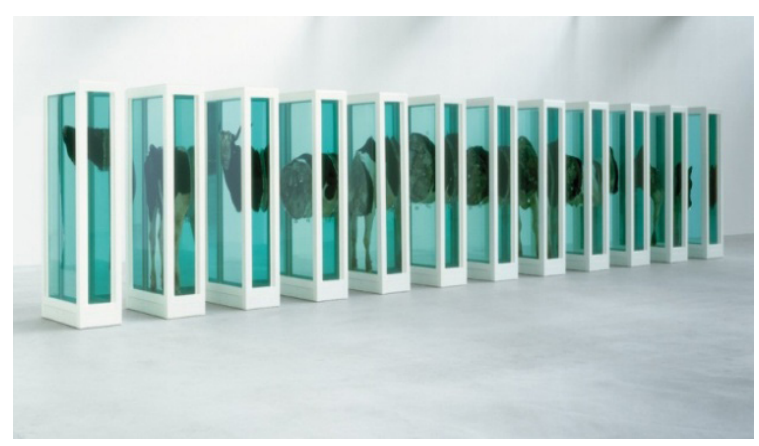

Figura 8 
La creatividad y puesta en escena preciosista del último de los asesinatos del caníbal lo convierten en uno de los más elaborados y hermosos de la serie ("Futamono", 2x06). Hannibal transforma, en este caso, el cuerpo del concejal, Sheldon Isley, en un cerezo y planta algunas flores en su estómago, todas ellas venenosas: Bella Dona en el corazón, Adelfa blanca en los intestinos y Ragwort en el hígado [Figura 9].

Según se explica, el político firmó un acuerdo en el que se aprobaba la destrucción de un criadero de aves para construir un aparcamiento, el mismo en el que se presenta su asesinato. Al igual que las flores, el tipo de árbol (cerezo) es escogido ex profeso por Hannibal, ya que simboliza, según los antiguos samuráis, la sangre, la fragilidad y lo efímero de la vida. El objetivo de Lecter, en definitiva, es siempre el mismo. A pesar de su crítica social, desea en todo momento "crear la belleza en el mal y arte en el gore" (Nahum García, 2018: 99).

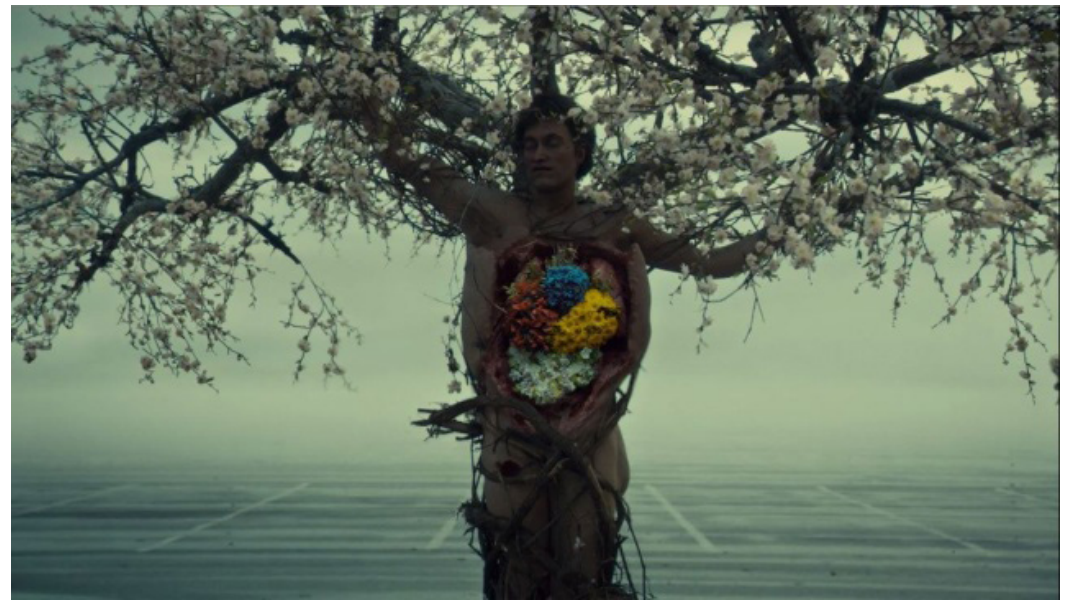

Figura 9

\subsection{Salvajismo y sofisticación en Hannibal}

Hannibal es símbolo del refinamiento aristocrático (Dellwing, 2019: 301) y su cultivada sensibilidad estética (Gracia, 2018: 78) lo distingue del resto de personajes y es elevado hacia una categoría superior. 
No sólo es la apariencia, la vestimenta y saber estar del personaje, lo que le confieren al distinguido psiquiatra esa aura de sofisticación y elegancia. Es un referente en medicina entre sus allegados y posee un gran dominio de la alta cultura como la música, la literatura, el arte o la gastronomía. Estas dos últimas artes forman parte de la seña de identidad del canibalismo de Lecter, pues practica, primero, su peculiar y artístico despiece humano para, posteriormente, ofrecer una exquisita y delicada presentación culinaria de sus víctimas.

\subsubsection{La (des)composición artística de Lecter}

El interés y conocimiento por el arte del protagonista se evidencia en las numerosas obras artísticas que decoran cada uno de los espacios con los que se le asocian: Leda y el cisne (1792) de François Boucher en el salón de la casa del protagonista, Los bañistas (1765) de Jean-Honoré Fragonard en su cocina o el tríptico de Utagawa Kunisada (1832) en su oficina. Uno de los ejemplos que resultan más llamativos en la ficción se lleva a cabo en el segundo episodio de la tercera temporada ("Primavera", 3x02). El propio título del capítulo hace referencia a esta bella representación que propone Hannibal de la obra que toma como referencia, La primavera (1477-1482) de Sandro Botticelli.

En esta ocasión, el caníbal recrea de manera muy detalla la mencionada obra renacentista. No obstante, no representa la pintura de Botticelli al completo, sino destaca únicamente a dos de los sujetos de la imagen. La víctima femenina de Lecter encarna a Cloris (la diosa de la pureza) que trata de huir de Céfiro (el dios del viento), profundamente enamorado de ella. Céfiro, convirtió a Cloris en esposa a la fuerza, la transformó en Flora y le entregó como regalo un bello jardín en el que sería eternamente primavera. Con su obra, el caníbal, desea remarcar dos conceptos: la fatalidad o el mal, representado en Céfiro, y la pureza o el bien, simbolizado en Cloris. El mensaje que traslada Lecter es que incluso la pureza puede ser corrompida. La que es considerada como una de las obras más bellas de la historia del arte (Trías, 1982: 65) es convertida, ahora, a manos del caníbal en una macabra escena del crimen. De este modo, Lecter pervierte el significado de la obra y crea una nueva concepción de la idea de la belleza, desligando la imagen de la muerte con su oscura y lúgubre representación tradicional [Figura 10]. 

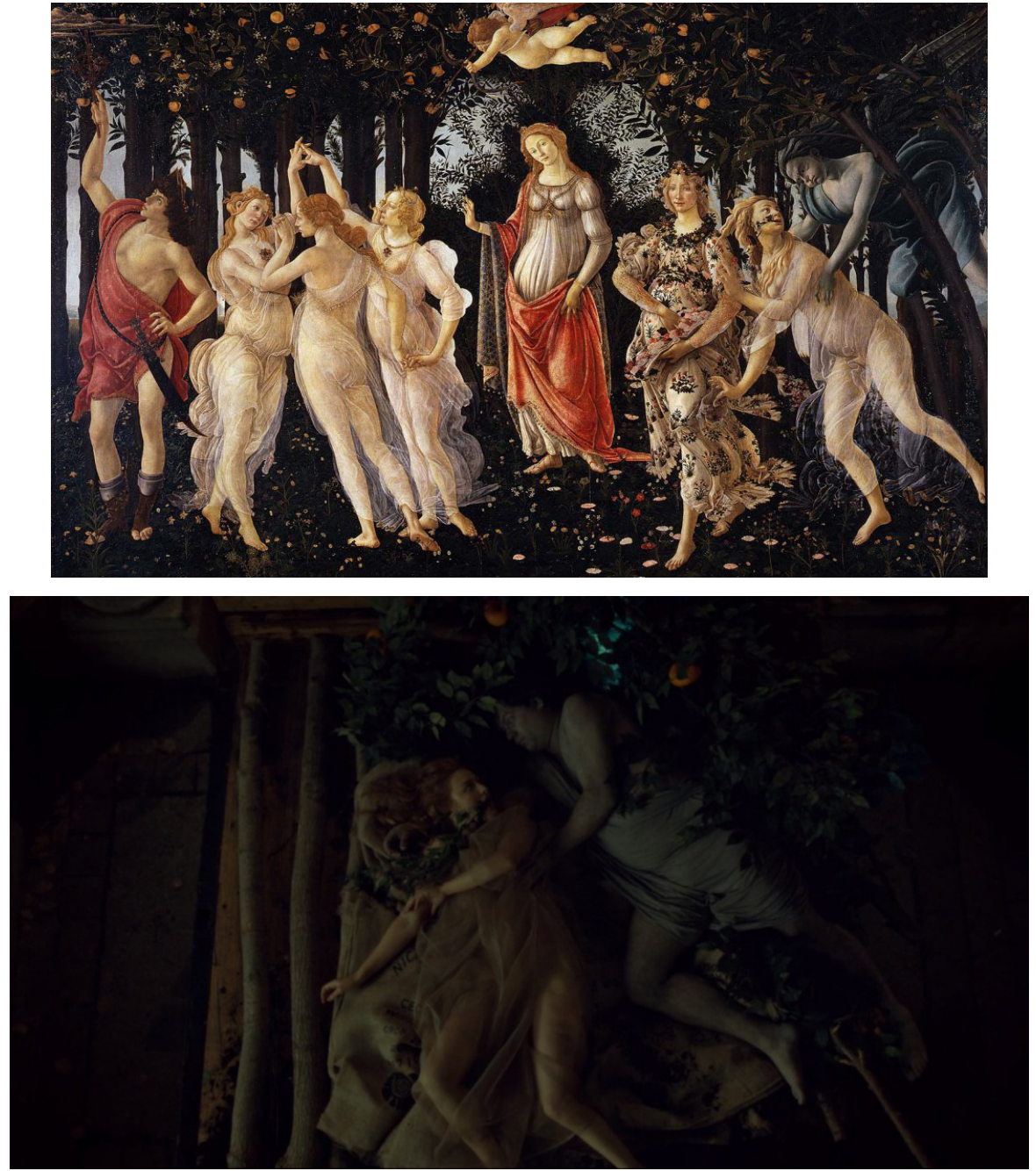

Figura 10

Por otra parte, no solo se narra la fábula de algunas deidades griegas, sino también alude, de manera más general, al nacimiento del ciclo de la vida (la primavera). Hannibal juega, precisamente, con esa idea al exponer los cuerpos sin vida de sus víctimas en una eterna, pero 
perecedera fotografía. Se activa, de esta manera, un mecanismo de lo sublime que impide una visión total del horror (Crisóstomo, 2015: 161). En palabras de Arnett, "el espectador, está incómodamente posicionado entre la curiosidad, el asombro y el miedo, y se convierte conscientemente en parte del espectáculo mismo" (2016: 28).

A juicio de McGinn, la piel funciona como un límite, una barrera infranqueable, para los seres humanos. El ejercicio más notable de Lecter es representar la muerte de una manera simbólica. Evita mostrar las entrañas, pues no solo produce un rechazo (asco) en la audiencia, sino que funciona como un anuncio de un peligro mortal. Lecter no mata, sino que crea puras obras de arte (Bainbridge, 2018: 605), dicho de otro modo, su barbarie es disfrazada y convertida en un ritual artístico.

\subsubsection{El chef caníbal}

La gastronomía, por su parte, posee una gran importancia en la ficción televisiva. Cada temporada es dividida en un tipo de cocina (francesa en la primera temporada, japonesa en la segunda e italiana en la primera mitad de la tercera), así como se emplean recetas culinarias para dar nombre a algunos episodios ${ }^{1}$. Es por medio del término "Kaikesi" empleado por Hannibal, en el mismo episodio que da nombre ("Kaikesi", 2x01), donde explica su interés por ofrecer una esmerada elaboración y puesta en escena de los platos. Este ritual culinario es practicado religiosamente por el caníbal a lo largo de la ficción y tiene como fin despertar el apetito de los espectadores, pese a ser conocedores de la procedencia de la carne.

La artistificación de la comida (Crisóstomo, 2014) alimenta, nunca mejor dicho, el disfrute visual. Induce a la audiencia a moverse entre los límites de la curiosidad y el miedo, entre el gusto y el rechazo (Arnett, 2016; Tirino, 2017). Se presenta "un horror tan hermosamente cocinado y minuciosamente emplatado que no podemos dejar de disfrutarlo" (MedinaContreras, 2018: 204). La belleza y el horror, lo exquisito y lo salvaje, son sutilmente cocinados y puestos a disposición de los invitados que el Dr. Lecter lleva a la mesa. Es una obra de arte lista para ser degustada. La experiencia sensorial completa que se experimenta en la serie se extiende a

${ }^{1}$ Son de mencionar los episodios "Amuse-Bouche" (2x02), "Entrée" (2x06), "Trou Normand" (2x09), "Buffet Froid" (2x10), "Tome-Wan" (2x12) o "Savoureux" (2x13). 
los espectadores a través de los simultáneamente apetitosos y repugnantes platos de Lecter (Balanzategui, 2018:670).

El canibalismo de Lecter es llevado al extremo y es representado también a través de la técnica del montaje, ya que la ficción es troceada y dispuesta bellamente para los espectadores (Lomax, 2018: 645). Ese montaje canibal se manifiesta muy claramente en una de las reuniones que celebran Hannibal y Jack Crawford (“Euf", 1x04). Ambos mantienen una animada conversación en donde bromean sobre el huidizo animal, el supuesto conejo, que compone el plato principal de su cena. En ese momento, una música chirriante -simulando el sonido de un cuchillointroduce los tres planos, de escasos tres segundos, que se intercalan a continuación: un hombre aparece huyendo a través de un bosque y en los dos siguientes Hannibal corta y cocina un pedazo de carne [Figuras 11-13]. Más que pertinente resulta la utilización de la técnica de cortede la serie que emula el selecto y violento modus operandi del caníbal.

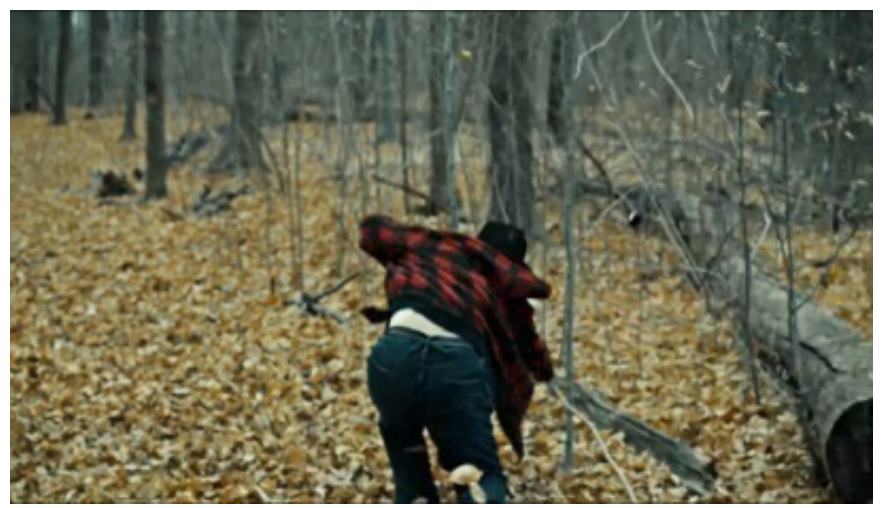

Figura 11 


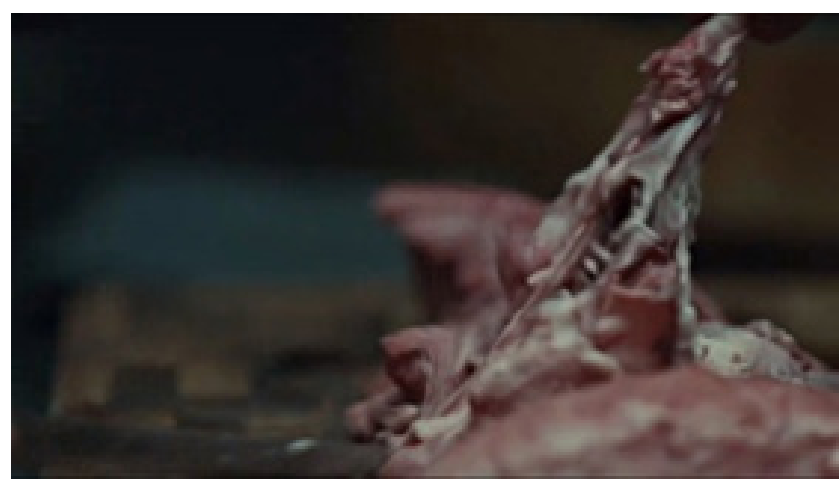

Figura 12

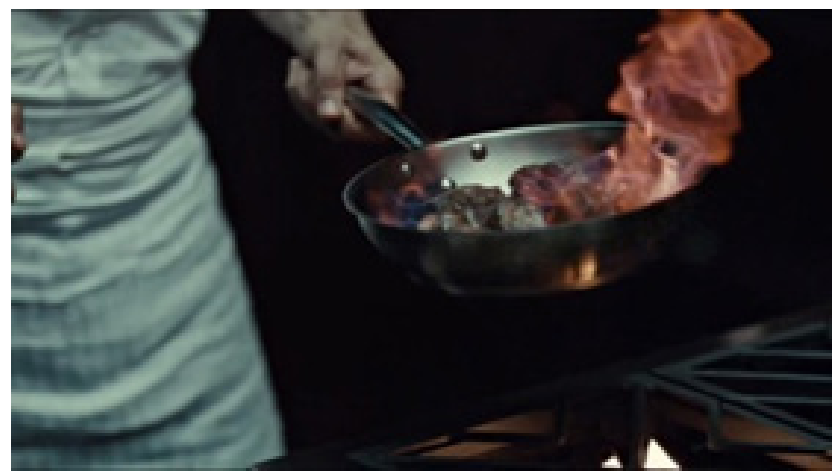

Figura 13

\section{CONCLUSIONES}

Hannibal es la perfecta conjunción entre el mundo intelectual más elevado (la cultura) y la forma más primitiva del ser humano (la naturaleza). Es ese médico asesino, juez amoral, esteta salvaje y perfecto villano protagonista a quien no deseamos dejar de contemplar. Es un personaje completamente liminal que se mueve en un continuo entre: entre la sofisticación y el salvajismo, entre lo culturalmente aceptado y rechazado, entre la vida y la muerte.

El protagonista-villano es a ojos de los espectadores el enemigo, el salvaje otro, que se contrapone al nosotros civilizado. Lecter actúa de manera racional en todas las esferas de su vida incluso en la más salvaje, 
pues sigue un cuestionable código ético en la selección de sus víctimas. En tanto en cuanto la figura de Lecter es absolutamente fronteriza - esteta salvaje, villano-protagonista o monstruo no-humano-también se difuminan los límites de los propios espectadores que son invitados a disfrutar del repulsivo arte que construye Hannibal. El canibalismo de Lecter funciona como el mayor símbolo de su salvajismo y es en la estetización de sus asesinatos y los muy exquisitos y repugnantes menús caníbales donde realiza su mayor representación teatral.

La ficción acompaña, también en el plano formal, el particular despiece del protagonista por medio del montaje caníbal. Ese montaje se complementa con la mencionada estética del horror que crea un continuo dilema moral en los espectadores, que se mueven entre la fascinación y el horror. Despierta, en otras palabras, la macabra atracción de la que hablaba Kolnai. A pesar de que los cuerpos humanos son dispuestos de forma poco natural, fragmentados y desfigurados, no generan un profundo rechazo. Este escenario de muerte es velado por la belleza ponzoñosa similar a la flor venenosa que coloca Lecter a una de sus víctimas- que genera un sentimiento de abyección en los espectadores, que los envenena y los corrompe.

Así, Hannibal logra revertir dos de las prácticas más rechazadas, el asesinato y el canibalismo, al embellecerlos por medio de los menús caníbales y los asesinatos (est)éticos. Lecter no solo es el otro, aquel que ejecuta las mayores perversiones posibles, sino también aquel que consigue transformar ese horror en puras obras de arte. El arte de Hannibal pervierte los significados originales de las obras de clásicas y contemporáneas a las que hace alusión. La paz y armonía que transmitían imágenes como La Primavera son disfrazadas por un horror embellecido. En un ejercicio de superioridad para con sus víctimas -los llamados groseros-, el caníbal desea representar la fugacidad de la vida por medio de la muerte y la caducidad de la belleza por medio de la putrefacción de los cuerpos.

El arte debe ser tomado como un concepto abierto, tal y como expresa Umberto Eco, que no se enmarca dentro de unos límites definidos y que va mutando en cada época y cultura. Es en la contemplación del arte contemporáneo donde salen a relucir, en palabras de Eugenio Trías, toda clase de sentimientos como lo siniestro, lo repugnante o incluso lo macabro. Y bajo esa premisa se erige el arte salvaje de Hannibal. En él, se aúna la belleza, por medio de la recreación de obras clásicas, y la perversión, 
al incorporar como pieza central de la obra al cadáver desmembrado y/o putrefacto. El objetivo es, ante todo, fundar un nuevo concepto de arte a través de las bellas, pero perecederas fotografías de muerte del caníbal.

\section{REFERENCIAS BIBLIOGRÁFICAS}

ARNETT, V. (2016). Cruel as a Cucumber: Food, Horror, and "Hannibal". Tesis doctoral: Maryland Institute College of Art.

BAINBRIDGE, J. (2018). "Making a Meal of the Law: Hannibal, Taste and the Limits of Legality". Quarterly Review of Film and Video 35.6, 601-613.

BALANZATEGUI, J. (2018). "The New Quality Crime Drama in the TVIV Era: Hannibal, True Detective, and Surrealism". Quarterly Review of Film and Video 35.6, 657-679.

BURKE, E. (2014). Indagación filosófica acerca del origen de nuestras ideas de la belleza y lo sublime. Madrid: Alianza Editorial.

CRISÓSTOMO, R. (2014). "Dr. Lecter y Mr. Dexter Morgan: mutaciones del héroe postclásico en la ficción televisiva". Área Abierta 14.2, 35-52.

(2015). "Apetito por lo horrible. Lo bello y lo siniestro en Hannibal". En La representación del horror. Semiótica, estética y estudios culturales, M. A. Broullón y P. Velasco (coords.), 156-67. Madrid: Ápeiron.

DELLWING, M. (2019). "It's Only Cannibalism if we're Equals: Consuming the Lesser in Hannibal'. En Globalized Eating Cultures,

J. Dürrschmidt \& E. York (eds.), 289-307. Cham, Switzerland:

Palgrave Macmillan.

ECO, U. (2005). Historia de la belleza. Barcelona: Lumen.

(2007). Historia de la fealdad. Barcelona: Lumen.

FREUD. S. (1974). "Lo siniestro". En Obras Completas, vol. VII, 24832505. Madrid: Biblioteca Nueva.

FUCHS, M. \& PHILLIPS, M. (2018). "It's Only Cannibalism If We're Equals: Carnivorous Consumption and Liminality in Hannibal". Quarterly Review of Film and Video 35.6, 614-629.

FULLER, B. (productor) (2013-2015). Hannibal [serie de televisión]. Estados Unidos: NBC. 
GRACIA, D. (2018). "Psychopath Aesthetics: the Example of the Cannibal". MHRA Working Papers in the Humanities 12, 70-79.

KRISTEVA, J. (2004). Poderes de la perversión. Madrid: Siglo XXI Editores.

LÉVI-STRAUSS, C. (1968). Mitológicas I. Lo crudo y lo cocido. México: Fondo de Cultura Económica.

(1995). Antropología estructural. Barcelona: Paidós.

LOMAX, T. (2018). "Cannibalizing Montage: Slicing, Dicing, and Splicing in Bryan Fuller's Hannibal". Quarterly Review of Film and Video 35.6, 644-656.

MEDINA-CONTRERAS, J. (2018). "Figura y fondo, realidad y ensoñación en Hannibal'. En La estética en las series contemporáneas, M. A. Huerta y P. Sangro (eds.), 89-210. Valencia: Tirant Humanidades.

NAHUM GARCÍA, A. (2018). "La estética del asco. Lo repugnante en la serialidad contemporánea". En La estética en las series contemporáneas, M. A. Huerta y P. Sangro (eds.), 189-210. Valencia: Tirant Humanidades.

NIETZSCHE, F. W. (2004). El ocaso de los ídolos. Madrid: Edimat.

OLESON, J. C. (2006). "Contemporary demonology: The criminological theories of Hannibal Lecter, part two". Journal of Criminal Justice and Popular Culture 13.1, 29-49.

PIÑEIRO-OTERO, T. (2016). "Intenciones e intersecciones de la música clásica en Hannibal de Bryan Fuller (NBC)". L'Atalante. Revista de Estudios Cinematográficos 21, 177-189.

TIRINO, M. (2017). "The Art of Killing. L'omicidio come performance identitaria nella serie" En Indelebilitacce: I mediae la rappresentazione della norte ai tempi dellarete, A. Napoli \& A. Santoro (eds.), 85-96. Funes: Ipermedium Libri.

TRÍAS, E. (1982). Lo bello y lo siniestro. Barcelona: Seix Barral.

Recibido el 2 de marzo de 2020.

Aceptado el 15 de abril de 2020. 